\title{
EJNSO
}

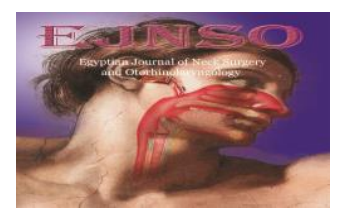

\section{ABO grouping as a risk factor for cancer larynx}

\author{
Mohammed Shaker Abd El Aal ${ }^{1}$, Mohammed Mahmoud Mohammed Roushdy ${ }^{1}$, \\ Maha Salah Mohamed El-Naggar ${ }^{2}$, Aliaa Ahmed Abd Allah Hussein ${ }^{3}$ \\ 1.Otorhinolaryngology, Faculty of Medicine- Assiut University. \\ 2.Clinical Oncology, Faculty of Medicine-Assuit University. \\ 3.Otorhinolaryngology Department El Mabara Hospital, Al Azhar University
}

\section{Abstract:}

Introduction: Laryngeal carcinoma is considered the second most common respiratory cancer following the lung cancer with predominance among males due to prevalence of smoking among men.

Objective: To evaluate $\mathrm{ABO}$ grouping as a risk factor for laryngeal carcinoma.

Patients and methods: Two groups, a patient group that enrolled 200 patients with cancer larynx based on clinical, radiological, and pathological assessment and a control group included 600 healthy persons. Data were collected by personal interviews and from the patient's records and from the control group. These data included: Age, Sex, Residence, Occupation, Smoking, any risk factor for cancer larynx as (GERD, alcohol consumption and spicy food), $\mathrm{ABO}$ grouping and $\mathrm{RH}$ typing (some from the records and some were done), presence of other diseases and Smoking status.

Results: Showed that the most frequent blood group in patients with cancer larynx was $\mathrm{O}$ positive (37.5\%) while the most frequent blood group in the control group was A positive $(31 \%)$. Blood group O positive (Odd's ratio= $1.36,95 \% \mathrm{CI}=1.09-$ $3.11 ; \mathrm{P}=0.01$ ).

Conclusions: Patients with blood group $\mathrm{O}+\mathrm{ve}$ were found to be more susceptible to have laryngeal cancer $(\mathrm{P}-\mathrm{V}$ alue $=0.01)$. So, the blood group $(\mathrm{O}+\mathrm{ve})$ is a risk factor for developing cancer larynx.

Key words: Cancer larynx, $\mathrm{ABO}$ grouping, Risk factors.

\section{Introduction}

In the head and neck region, laryngeal carcinoma is the second most common malignancy. ${ }^{1,2}$

In the United States of America, the laryngeal cancer is typically presented in males aged 50s to 60s with a history of smoking and/or alcohol consumption. The male predilection for the disease has decreased from a
15: 1 to less than 5:1 (male: female ratio) currently. This demographic change could be attributed to increased rates of smoking among women and their increased exposure to toxic work environments. ${ }^{1,3}$

It has been found that $\mathrm{ABO}$ grouping is a risk factor for different types of cancer. Group A was found to be associated with increased the risk of 
gastrointestinal malignancies including gastric and pancreas cancers. ${ }^{4,5}$

A strong association between salivary gland tumors and blood group A, was hypothesized by Pinkston and Cole. ${ }^{6}$

So, we conducted this study to discover if there is a relation between $\mathrm{ABO}$ blood group and laryngeal cancer or not.

\section{Patients and Methods:}

This study was performed at Otorhinolaryngology and Oncology department of Assiut University Hospital to evaluate $\mathrm{ABO}$ grouping as a risk factor for cancer larynx. It was conducted in the period between December 2016 and April 2019 and included two groups, a patient group that enrolled 200 patients with cancer larynx based on clinical, radiological and pathological assessment and a control group included 600 healthy persons and after obtaining approval from the institutional ethics committee. Study design: Case- control study.

Study period: From December 2016 to April 2019.

Sampling method: simple random sampling.

\section{Sample size:}

Patient group included 200 consecutive patients who were diagnosed as having cancer larynx based on clinical, radiological and pathological assessment.

Control group included 600 cancer free persons.

\section{Selection of cases:}

- Cases of cancer larynx. They were collected from the department of Otorhinolaryngology at AUH, the department of Oncology at AUH, Health insurance hospital at El Minya governate, El Mabara insurance hospital and the military center in Mankabad.

Selection of controls:
- Persons with no caner and no laryngeal diseases. They were collected from the department of Otorhinolaryngology at AUH and El Mabara hospital.

\section{Study tools:}

Data collection: data were collected by personal interview or from the patient's records and from the control group. These data included:

- Age.

- Sex.

- Residence.

- Occupation.

- Smoking.

- Any risk factor for cancer larynx as (gastro esophageal reflux, alcohol consumption and spicy food).

- $\mathrm{ABO}$ grouping and $\mathrm{RH}$ typing (some from the records and some were done).

- The presence of other diseases.

Smoking status was classified as:

- Non-smokers, who smoked less than 100 cigarettes in their lifetime and are not currently smoking.

- X- smokers, who smoked 100 cigarettes or more in their lifetime and are currently nonsmokers.

- Current smokers, who smoked 100 cigarettes or more in their lifetime and are currently smokers. 7

- Status of smoking exposure was classified as:

- Mild smoker ( $\leq 10 \quad$ cigarettes daily).

- Moderate smoker $\quad(\leq 20$ cigarettes daily).

- Heavy smoker (>20 cigarettes daily). ${ }^{8}$

\section{Statistical analysis :}

SPSS (Statistical Package for the Social Science, version 20, IBM, and Armonk, New York) was used to 
analyze the collected. Mean \pm SD or median (range) were used to express continuous data while frequency (percentage) was used to express nominal data.

to compare the nominal data of different groups in the study, we used $\mathrm{Chi}^{2}$-test while student t-test was used to compare mean of different two groups. Multivariate regression analysis was used to determine possible risk factors for cancer larynx. Level of confidence was kept at 95\% and $\mathrm{P}$ value was considered significant if $<0.05$.

\section{Results:}

\section{Possible Risk Factors for Cancer}

\section{Larynx:}

\section{Smoking Status in the Studied}

\section{Groups:}

The results were shown in Table $\mathbf{1}$.

Table 1: Smoking status in studied groups

\begin{tabular}{|c|c|c|c|}
\hline & $\begin{array}{l}\text { Patients group } \\
\quad(n=200)\end{array}$ & $\begin{array}{c}\text { Control group } \\
(n=600)\end{array}$ & $P$ \\
\hline Smoking status & & & 0.01 \\
\hline Nonsmoker & $31(15.5 \%)$ & $194(32.3 \%)$ & \\
\hline Passive smoker & $6(3 \%)$ & $83(13.8 \%)$ & \\
\hline X-smoker & $36(18 \%)$ & $67(11.2 \%)$ & \\
\hline Current smoker & $127(63.5 \%)$ & $256(42.6 \%)$ & \\
\hline Mild & $10(5 \%)$ & $57(9.5 \%)$ & \\
\hline Moderate & $31(15.5 \%)$ & $71(11.8 \%)$ & \\
\hline Heavy & $86(43 \%)$ & $128(21.3 \%)$ & \\
\hline
\end{tabular}

\section{Other Risk Factors:}

It was noticed that alcohol intake was insignificantly higher in patients with cancer larynx in comparison to the control group (9\% vs. $5.8 \%$; $\mathrm{P}=$ 0.09).

There was a history of treatment of GERD in $83(41.5 \%)$ patients and 216 $(36 \%)$ healthy controls with insignificant differences between both groups.

Consumption of spicy food was significantly higher in the patients' group (97 (48.5\%) vs. 198 (33\%); $\mathrm{P}=$ 0.04) as shown in Figures 1 and 2.

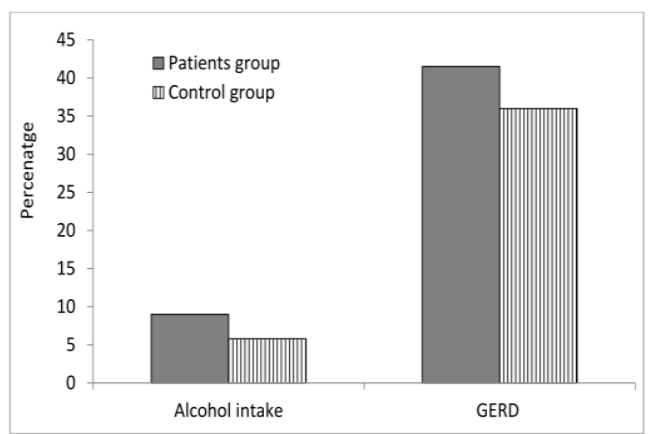

Figure 1: Risk factors for cancer larynx in the current study

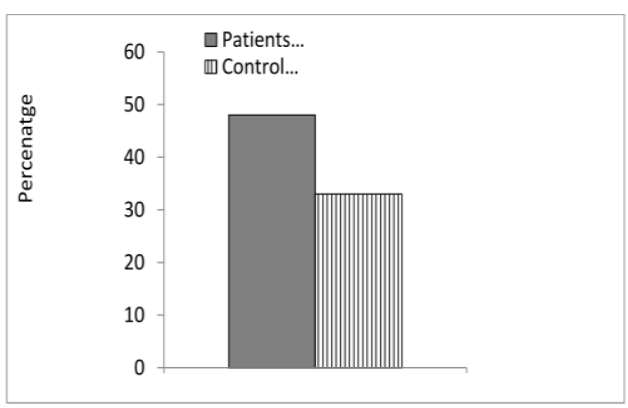

Figure 2: Spicy food consumption in the current study

\section{ABO Grouping of the Studied groups}

It was noticed that the most frequent blood group in patients with cancer larynx was $\mathrm{O}$ positive $(37.5 \%)$ while the most frequent blood group in control group was A positive (31\%). Table 2 summarizes the ABO grouping of the studied groups.

Table 2: ABO grouping of studied groups

\begin{tabular}{|c|c|c|c|}
\hline & $\begin{array}{c}\text { Patients } \\
\text { group }(\mathbf{n}= \\
\mathbf{2 0 0})\end{array}$ & $\begin{array}{c}\text { Control group } \\
(\mathbf{n = 6 0 0})\end{array}$ & $\boldsymbol{P}$ \\
\hline ABO grouping & $48(24 \%)$ & $\mathbf{1 8 6}(\mathbf{3 1 \%})$ & $\mathbf{0 . 0 1}$ \\
A positive & $2(1 \%)$ & $17(2.8 \%)$ & \\
A negative & $25(12.5 \%)$ & $55(9.2 \%)$ & \\
AB positive & $1(0.5 \%)$ & $10(1.7 \%)$ & \\
AB negative & $47(23.5 \%)$ & $149(24.8 \%)$ & \\
B positive & $1(0.5 \%)$ & $5(0.8 \%)$ & \\
B negative & $\mathbf{7 5 ( 3 7 . 5 \% )}$ & $171(28.5 \%)$ & \\
O positive & $1(0.5 \%)$ & $7(1.2 \%)$ & \\
O negative & \multicolumn{2}{|}{} \\
\hline
\end{tabular}

Data was expressed in the form of frequency (percentage). $P$ value was significant if $<0.05$ 
Multivariate Regression Analysis for Prediction of Cancer Larynx:

It was noticed that the following predictors were considered risks factors for cancer larynx with R2 $=0.67$.

- Smoking (odd's ratio $=3.73,95 \%$ CI $($ confidence interval $)=1.79$ $7.23 ; P=0.01)$.

- Male sex (odd's ratio $=2.66,95 \%$ $\mathrm{CI}=1.46-4.92 ; P=0.01)$.

- Blood group O positive (odd's ratio $=1.36,95 \% \mathrm{CI}=1.09-3.11$; $P=0.01)$. (Table 3)

Table 3: Multivariate regression analysis for prediction of cancer larynx

\begin{tabular}{|c|c|c|c|}
\hline Predictors & $\begin{array}{c}\text { Odd's } \\
\text { ratio }\end{array}$ & $\begin{array}{c}\mathbf{9 5 \%} \\
\text { confidence } \\
\text { interval }\end{array}$ & $\boldsymbol{P}$ \\
\hline Male sex & $\mathbf{2 . 6 6}$ & $\mathbf{1 . 4 6 - 4 . 9 2}$ & $\mathbf{0 . 0 1}$ \\
\hline Smoking & $\mathbf{3 . 7 3}$ & $\mathbf{1 . 7 9 - 7 . 2 3}$ & $\mathbf{0 . 0 1}$ \\
\hline Spicy food & 1.57 & $1.09-2.27$ & 0.14 \\
\hline $\begin{array}{c}\text { O positive } \\
\text { blood group }\end{array}$ & $\mathbf{1 . 3 6}$ & $\mathbf{1 . 0 9 - 3 . 1 1}$ & $\mathbf{0 . 0 1}$ \\
\hline value was significant if $<0.05$ & \\
\hline
\end{tabular}

\section{Discussion :}

The exact cause of laryngeal cancer is still unknown. However, several cofactors (mainly smoking and alcohol intake), are clearly associated with increased incidence in cancer larynx. Both increase the risk of cancer in a dose-dependent way. Infections from herpes simplex and Human Papilloma virus, gastroesophageal reflux disease, steam and heat inhalation, thermal burns and exposure to ionizing radiation, asbestos, nickel, textile fibers and various chemicals, like formaldehyde, vinyl chloride and benzopyrenes, have also been considered as etiological factors. ${ }^{3}$

As regarding smoking, our study found that $(63.5 \%)$ of patients with laryngeal cancer were current smokers, $(18 \%)$ were $\mathrm{x}$-smokers and $(3 \%)$ were passive smokers while in controls $(42.7 \%)$ were current smokers, $(11.2 \%)$ were $\mathrm{x}$-smokers and $(13.8 \%)$ were passive smokers, a statistical significance was found between patients and control group regarding smoking $(\mathrm{P}-$ Value $=0.01)$ this result is compatible with Koyanagi et al. (2016) that stated that smoking is considered the major etiological factor for cancer larynx. ${ }^{9}$ According to Altieri et al (2002) and Licitra et al (2003) about $90 \%$ of cancer larynx incidence could be avoided by preventing tobacco smoking and by changing smoking status. ${ }^{10-11}$

As regarding Alcohol intake, it is a major risk factor for incidence of cancer larynx 10, 12 which is not compatible with our results. In this study alcohol consumption among patients with cancer larynx was $(9 \%)$ while non-drinker were $(91 \%)$ this result is compatible with multiple studies that stated that the pattern of incidence and rate of mortality of upper aerodigestive tract (UADT) cancers is different among Africans especially Algerian, Tunisian, Moroccan and Egyptians because they do not drink alcohol for religious reasons. $^{13-14}$

In this study history of treatment from GERD was included in the risk factors of cancer larynx, $(41.5 \%)$ of the patients were with history of treatment from GERD and in control group $(36 \%)$ also were with history of treatment from GERD. Many studies found that GERD or its variation known as laryngopharyngeal reflux (LPR) is a potential risk factor for cancer larynx as in case control study conducted by Mursalin et al (2018) on 290 laryngeal cancer patients and 2440 lung cancer patients as controls, they found that reflux disease was more prevalent among laryngeal cancer patients than lung cancer patients and there was a modest association between laryngeal cancer and GERD which was statistically significant $(\mathrm{P}=$ 0.003). ${ }^{15}$ 
In contrast a case control study was conducted by Francis et al (2011) has found no association between incidence of cancer larynx and GERD but, they suggested that affection of subsites within the larynx specially glottic tumors may be caused by GERD. ${ }^{16}$

The consumption of spicy food was investigated among patients and controls, patients consumed spicy food were $(48.5 \%)$ while in control group they were $(33 \%)$, these results are in agreement with the results of a case control study by Kapil et al (2005) for evaluation of risk factors in cancer larynx in India in which patients consumed spicy food were (50.2\%) while in control group they were $(30.2 \%)$ and they found that spicy foods were found to be positively related to the risk of cancer larynx. ${ }^{17}$

In this study, blood group A+ve (31\%) was found to be predominant among the control group followed by blood group O+ve (28.5\%). These findings are in agreement with the Egyptian study conducted by Homouda in (2012) about the distribution of $\mathrm{ABO}$ and Rh-D blood groups in healthy Egyptian population found that the Blood group A was the most predominant $(36.9 \%)$ followed by blood group O (30.7\%), B (23.2\%) and AB (9.2\%). The majority $(92.2 \%)$ of the subjects was $\mathrm{Rh}(\mathrm{D})$ positive and only $(7.8 \%)$ were $\mathrm{Rh}$ negative. ${ }^{18}$ These findings are also in agreement with another Egyptian study conducted by Swelem et al (2018), were A $(39.4 \%)$, $\mathrm{O}(25.9 \%), \quad \mathrm{B}(24.1 \%) \quad$ and $\mathrm{AB}(10.6 \%)$, while the $\mathrm{Rh} \mathrm{D}$ negative incidence was (14.4\%). ${ }^{19}$ In contrast our findings are not in agreement with the study done by Mahmoud et al. (1987) in E1-Dakhlya they found that blood group $\mathrm{O}>\mathrm{A}>\mathrm{B}>\mathrm{AB} .^{20}$

In our study, a significant association was found between $\mathrm{ABO}$ blood groups and the incidence of cancer larynx with higher incidence in subjects with blood group $\mathrm{O}+\mathrm{ve}(\mathrm{OR}$ of $1.36,95 \% \mathrm{CI}=1.09-3.11, \mathrm{P}=0.01$ ).

Our findings are not in agreement with the findings of the Polish study conducted by Pyd et al. (1995), which concluded that blood group (A) was significantly present with glottic cancer compared to supraglottic and subglottic cancer. $^{21}$

Also, our results differ from the results made by Adam et al (2012) on 143 patients with cancer larynx and 450,000 controls in USA, who found that there was no significant association between patient's blood group type and laryngeal squamous cell carcinoma incidence. ${ }^{22}$

A case control study was made by Singh et al (2014) on 362 patients with head and neck cancers including 42 patients with cancer larynx and 400 controls indicated that as potential risk factor for developing of oral, esophageal and salivary gland cancers is blood group (A) while blood group (B) is a potential risk factor for cancer. $^{23}$

Also, an Iranian case control study was done by Saki et al (2015) studied the relation between $\mathrm{ABO}$ blood groups and cancer larynx on 66 patients with cancer larynx and 148 healthy controls they found no significant relationship between cancer larynx and $\mathrm{ABO}$ blood groups in Iranian population. ${ }^{24}$

Another case control study was made by Kakava et al (2016) on 195 patients with head and neck cancers including 103 patients with cancer larynx and 801 controls. This study demonstrated that different blood groups are associated with different risks for head and neck cancer and people with blood group (A) are at higher risk to develop head and neck cancer followed by those with blood group $\mathrm{B}, \mathrm{AB}$ and $\mathrm{O} .{ }^{25}$ 
Our study found that cancer larynx is more among patients with blood group (O+ve) while in the study done by Pyd et al 1995 cancer larynx was more in blood group (A), and the study conducted by Singh et al (2014) blood group (B) was a potential risk factor for laryngeal cancers. Another study was made by Kakava et al (2016) found that people with blood group (A) are at higher risk to develop head and neck cancer. Despite ABO is a risk factor for cancer larynx in our study, these results conflicted by other studies. 21, 23, 25 More studies are needed in this issue to solve this debate.

\section{Conclusion:}

The analysis of blood groups distribution among patients with cancer larynx and controls showed that laryngeal cancer was found to be more among patients with blood group $\mathrm{O}$ $+v e$. So, patients with blood group (O+ve) having laryngeal symptoms should be examined for early detection of laryngeal carcinoma.

Also, our study emphasized the importance of other risk factors as smoking and spicy food with statistically significant results.

\section{Financial support and sponsorship:}

No financial support was obtained from any source.

\section{Conflicts of interest:}

No potential conflicts of interest.

\section{Reference:}

1. Tawab HMA, ElMessih MWA, AlNaggar NA, et al. Study of the epidemiology and management of laryngeal cancer in Kasr Al-Aini Hospital. The Egyptian Journal of Otolaryngology. 2014;30(3):208-14.

2. Chu EA, Kim YJ. Laryngeal cancer: diagnosis and preoperative work-up.
Otolaryngologic Clinics of North America. 2008;41(4):673-95.

3. Mastronikolis NS, Papadas TA, Goumas PD, et al. Head and neck: Laryngeal tumors: an overview. Atlas Genet Cytogenet Oncol Haematol. 2009;13(11):888-93.

4. Wolpin BM, Kraft P, Gross M, et al. Pancreatic cancer risk and $\mathrm{ABO}$ blood group alleles: results from the pancreatic cancer cohort consortium. Cancer research. 2010;70(3):1015-23.

5. Hallstone AE, Perez EA. Blood type and the risk of gastric disease. Science. 1994;264(5164):1386-7.

6. Pinkston JA, Cole P. ABO blood groups and salivary gland tumors (Alabama, United States). Cancer Causes \& Control. 1996;7(6):572-4.

7. Kim Y, Cho WK. Effects of smoking on disease risk among south Korean adults. Tobacco induced diseases. 2018;16.

8. Solak ZA, Kabaroğlu C, Çok GÜ, et al. Effect of different levels of cigarette smoking on lipid peroxidation, glutathione enzymes and paraoxonase 1 activity in healthy people. Clinical and experimental medicine. 2005 Oct 1;5(3):99-105.

9. Koyanagi $\mathrm{YN}$, Matsuo $\mathrm{K}$, Ito $\mathrm{H}$, et al. Cigarette smoking and the risk of head and neck cancer in the Japanese population: a systematic review and meta-analysis. Jpn J Clin Oncol. 2016;46(6):580-95.

10.Licitra L, Bernier J, Grandi C, et al. Cancer of the larynx. Critical Reviews in Oncology / Hematology. 2003;47(1):65-80.

11.Altieri A, Bosetti C, Talamini R, et al. Cessation of smoking and drinking and the risk of laryngeal cancer. British journal of cancer. 2002;87(11):1227.

12.La Vecchia C, Zhang ZF, Altieri A. Alcohol and laryngeal cancer: an update. European Journal of Cancer Prevention. 2008;17(2):116-24.

13. Menvielle G, Kunst AE, Stirbu I, et al. Socioeconomic inequalities in alcohol related cancer mortality among men: to what extent do they differ between Western European populations? International journal of cancer. 2007;121(3):649-55. 
14.Bouchardy C, Parkin DM, Wanner P, et al. Cancer mortality among north African migrants in France. International journal of epidemiology. 1996;25(1):5-13.

15.Anis MM, Razavi M-M, Xiao X, et al. Association of gastroesophageal reflux disease and laryngeal cancer. World Journal of Otorhinolaryngology-Head and Neck Surgery. 2018;4(4):278-81.

16. Francis DO, Maynard C, Weymuller EA, et al. Reevaluation of gastroesophageal reflux disease as a risk factor for laryngeal cancer. The Laryngoscope. 2011;121(1):102-5.

17. Kapil U, Singh P, Bahadur S, et al. Assessment of risk factors in laryngeal cancer in India: a case-control study. Asian Pac J Cancer Prev. 2005;6(2):202-7.

18. Homouda FA. Distribution of $\mathrm{ABO}$ and Rh-D blood groups in healthy Egyptian population. CU Theses. 2012.

19. Swelem O, Goubran F, Younis S, et al. $\mathrm{ABO}, \mathrm{RH}$ phenotypes and kell blood groups frequencies in an Egyptian population. Hematology \& Transfusion International Journal. 2018;6(2):71-75.

20.Mahmoud L-N, Ibrahim A-K, Ghonem $\mathrm{H}$, et al. Human blood groups in Dakahlya, Egypt. Annals of human biology. 1987;14(6):487-93.
21.Pyd M, Rzewnicki I, Suwayach U. ABO blood groups in patients with laryngeal and hypopharyngeal cancer. Otolaryngologia polska $=$ The Polish otolaryngology. 1995; 49:396-8.

22. Adam S, Wilson K, Overholser S, et al. Are laryngeal squamous cell carcinoma incidence and patient mortality a function of $\mathrm{ABO}$ blood grouping? A retrospective study. The Journal of Laryngology \& Otology. 2012;126(2):180-4.

23.Singh K, Kote S, Patthi B, et al. Relative risk of various head and neck cancers among different blood groups: an analytical study. Journal of clinical and diagnostic research: JCDR. 2014;8(4):25-8.

24.Saki Nader, Darakhshandeh Vita , Araghi Somayeh, et al. Assessment of association between $\mathrm{ABO}$ blood groups and laryngeal cancer among Iranian population. Journal of Pure and Applied Microbiology. 2015 Sep 1;9(3):2001-4.

25. Kakava K, Karelas I, Koutrafouris I, et al. Relationship between ABO blood groups and head and neck cancer among Greek patients. J BUON. 2016;21(3):594-6. 